\title{
Distância genética entre cultivares de arroz irrigado em experimentos conduzidos a campo e em casa de vegetação
}

\author{
Genetic distance between rice cultivars in experiments conducted in the field and in the \\ greenhouse
}

\author{
Eduardo Anibele Streck*, Paulo Henrique Karling Facchinello, Gabriel Almeida Aguiar, Tuise Kuhn \\ Krüguer \& Ariano Martins de Magalhães Júnior
}

Empresa Brasileira de Pesquisa Agropecuária, Pelotas, RS, Brasil. *Autor para correspondência: streck.eduardo@gmail.com.

Submissão: 19/04/2016 | Aceite: 13/06/2018

\begin{abstract}
RESUMO
Objetivou-se nesse estudo estimar a distância genética com base em distintos caracteres fenotípicos e descritores agronômicos, em experimentos a campo, em casa de vegetação e análise conjunta de ambientes em arroz irrigado. Neste estudo foram avaliados 16 genótipos de arroz irrigado em experimentos a campo e em casa de vegetação. Nas duas condições experimentais foram mensurados 24 caracteres, sendo, 16 considerados quantitativos e oito considerados qualitativos. A partir dos dados fenotípicos foram obtidas três matrizes de distâncias de Mahalanobis (baseadas nos caracteres mensurados a campo, casa de vegetação e análise conjunta), que posteriormente originaram três dendrogramas, utilizando o método de agrupamento das médias das distâncias (UPGMA - Unweighted Pair Group Method using Arithmetic averages). A associação das matrizes de distância genética foi realizada pelo teste de Mantel. Assim, as estimativas da distância genética utilizadas, mostraram-se adequadas no agrupamento dos genótipos, evidenciando estreita distância genética entre as cultivares de arroz irrigado avaliadas. As matrizes de distância genética entre os genótipos com base nos caracteres qualitativos aferidos a campo, em casa de vegetação e a conjunta de ambos os ambientes, evidenciaram associação elevada entre si. Existe efeito do ambiente em caracteres de herança genética quantitativa.
\end{abstract}

PALAVRAS-CHAVE: Oryza sativa, variabilidade genética, dissimilaridade genética, caracteres agronômicos, caracterização morfológica.

\begin{abstract}
The objective of this study was to estimate the genetic distance of irrigated rice based on different phenotypic characters and agronomic descriptors in field experiments and a greenhouse, with joint analysis of environments. In this study, 16 genotypes of rice were evaluated in the field and in greenhouse. In both experimental conditions were measured 24 characters, 16 considered quantitative and eight qualitative. From the phenotypic data were obtained three matrices of Mahalanobis distances (based on characters measured for field, greenhouse and joint analysis), which originated three dendrograms using the Unweighted Pair Group Method using Arithmetic averages (UPGMA). The correlation between genetic distance matrices was performed by the Mantel test. Thus, the estimates of genetic distance used were adequate in the grouping of genotypes, evidencing a narrow genetic distance between the irrigated rice cultivars evaluated. The genetic distance matrices between genotypes based on the qualitative characteristics measured for field, greenhouse and joint analysis of both environments showed a high correlation. There is environmental effect on characteristics of quantitative genetic inheritance.
\end{abstract}

KEYWORDS: Oryza sativa, genetic variability, genetic dissimilarity, agronomic traits, morphological characterization.

\section{INTRODUÇÃO}

O arroz (Oryza sativa L.) é a base da dieta e a principal fonte de proteínas e carboidratos para mais da metade da população mundial, tendo importância relativa mais evidenciada em países pobres e em desenvolvimento (LEE et al. 2011).

Para atender as crescentes demandas pelo cereal, ganhos genéticos são necessários, seja via 
melhoramento tradicional ou com auxílio da biotecnologia. Nas últimas décadas houveram incrementos significativos no potencial de produtividade da cultura, no entanto, apenas um grupo restrito de genótipos geneticamente semelhantes vem sendo utilizado exaustivamente como genitores, apesar da extensa variabilidade genética disponível nos bancos de germoplasma (BRONDANI et al. 2006).

No melhoramento de plantas, a variabilidade genética é de essencial interesse para obtenção de progressos através da seleção natural ou artificial, viabilizando o emprego de técnicas que possibilitem a identificação de genótipos superiores (HARTWIG et al. 2007).

A estimativa de distância genética baseada em caracteres morfológicos entre os genótipos é apontada como uma forma de prever a variabilidade genética (HOSAN et al. 2010). O inconveniente das avaliações baseadas na manifestação dos caracteres fenotípicos diz respeito à elevada influência do ambiente, dependendo do caráter e da espécie avaliada, o que pode reduzir a precisão das estimativas de parâmetros genéticos quantitativos, indicando a necessidade da avaliação dos genótipos por mais de um ambiente e/ou ano, sendo tão mais segura quanto maior o número de ambientes e/ou anos avaliados. No entanto, estudos de distância genética com base no emprego de caracteres fenotípicos são os procedimentos mais utilizados pelos melhoristas de plantas.

Dentre os procedimentos estatísticos mais utilizados na estimativa da distância genética com base em caracteres fenotípicos, está a distância generalizada de Mahalanobis $\left(\mathrm{D}^{2}\right)$ e a distância Euclidiana. Sendo que, a primeira oferece vantagem por levar em consideração o efeito do ambiente e a possibilidade de correlação entre os caracteres, porém, necessita de ensaios experimentais com repetições.

A partir das estimativas de distância entre cada par de genótipos estudado, os dados são apresentados em uma matriz de dissimilaridade, deste modo, a visualização e interpretação das distâncias pode ser facilitada pela utilização de um método de agrupamento e/ou dispersão gráfica.

Neste sentido, objetivou-se nesse estudo estimar a distância genética em um conjunto de cultivares superiores de arroz irrigado, com base em distintos caracteres fenotípicos e descritores agronômicos, em experimentos a campo e em casa de vegetação.

\section{MATERIAL E MÉTODOS}

Neste estudo foram empregados 16 genótipos de arroz irrigado, sendo eles: IAS 12-9 Formosa, BR IRGA 409, BR IRGA 410, BR IRGA 411, BR IRGA 412, BR IRGA 413, BR IRGA 414, BRS 6 "Chuí", BRS 7 "Taim", BRS Ligeirinho, BRS Agrisul, BRS Bojuru, BRS Firmeza, BRS Atalanta, BRS Pelota e BRS Querência. Estes genótipos foram lançados pelo programa de melhoramento genético da Embrapa Clima Temperado (seis cultivares lançadas em parceria com o Instituto Rio Grandense do Arroz) e representam constituições genéticas superiores da espécie Oryza sativa L.

Para avaliação fenotípica das cultivares utilizadas no estudo, foram conduzidos experimentos a campo e em casa de vegetação. Nas duas condições experimentais foram mensurados 24 caracteres, sendo, 16 considerados quantitativos: estatura de planta, comprimento do colmo, comprimento da folha bandeira, largura da folha bandeira, espessura do colmo, comprimento da panícula, ciclo vegetativo (da emergência até $50 \%$ da floração), massa de panícula, número de grãos degranados, número de grãos por panícula, número de grãos estéreis, massa de mil grãos, comprimento de grãos sem casca, largura de grãos sem casca, espessura do grão sem casca, relação de comprimento por largura do grão; e, oito considerados qualitativos, representados por descritores agronômicos da cultura do arroz: cor da folha, pubescência da folha, ângulo da folha bandeira, tipo de panícula, exerção da panícula, pubescência das glumelas, coloração das glumelas e forma do grão.

A campo, o delineamento experimental empregado foi o de blocos completamente casualizados com três repetições, sendo as parcelas compostas por quatro fileiras de $5 \mathrm{~m}$ com espaçamento de $0,17 \mathrm{~m}$ entre linhas. A área útil da parcela foi constituída pelos $4 \mathrm{~m}$ centrais das duas fileiras internas. A densidade de semeadura foi de $120 \mathrm{~kg} \mathrm{ha}^{-1}$, sendo utilizada uma semeadora mecânica de parcelas, em sistema convencional de plantio. Utilizou-se o sistema de irrigação por inundação permanente até o estádio de final de maturação dos genótipos.

O experimento em casa de vegetação também foi conduzido em blocos completamente casualizados com três repetições, sendo cada parcela composta por um balde contendo cinco plantas (equivalente a mesma densidade de plantas utilizada à campo). Nesta situação, todas as plantas foram utilizadas para coleta dos dados. $\mathrm{O}$ solo dos baldes foi coletado na área de pesquisa do campo experimental da Estação Terras Baixas da Embrapa Clima Temperado, sendo representativo ao cultivo de arroz irrigado (hidromórfico). Após o estádio V4, foi aplicado lâmina de água permanente nos baldes.

Os dados dos caracteres qualitativos que exibiram classes distintas no conjunto dos genótipos 
avaliados foram utilizados para estimativa da distância genética, de acordo com o coeficiente $\mathrm{R}$ de dissimilaridade genética, sob três distintos procedimentos: i) dos caracteres aferidos a campo; ii) dos caracteres aferidos em casa de vegetação e; iii) da análise conjunta dos dois experimentos. Desta forma, foram obtidas três matrizes de distâncias de Mahalanobis $\left(D^{2}\right)$. Todas as análises estatísticas foram realizadas por meio do Aplicativo Computacional em Genética e Estatística de GENES (CRUZ 2013). Com base nas matrizes de distâncias genéticas geradas, foram construídos três dendrogramas, utilizando o método de agrupamento das médias das distâncias (UPGMA). Para a estimativa do ajuste entre a matriz de dissimilaridade e o dendrograma gerado, foi calculado o coeficiente de correlação cofenética ( $r$ ) (SOKAL \& ROHLF 1962), utilizando o programa computacional NTSYS pc 2.1 (ROHLF 2000).

Os dados dos caracteres quantitativos, primeiramente, foram submetidos à análise de variância univariada, e posteriormente às médias dos genótipos foram empregadas para estimar a distância generalizada de Mahalanobis $\left(\mathrm{D}^{2}\right)$ entre todos os pares de genótipos. A distância genética baseada nos caracteres quantitativos foi analisada em três distintos procedimentos, considerando a padronização (transformação) das variáveis: i) dos caracteres aferidos a campo; ii) dos caracteres aferidos em casa de vegetação e; iii) da análise conjunta dos dois experimentos. Desta forma, foram obtidas três matrizes de distâncias de Mahalanobis $\left(\mathrm{D}^{2}\right)$. Todas as análises estatísticas foram realizadas por meio do Aplicativo Computacional em Genética e Estatística de Genes (CRUZ 2013). Com base nas matrizes de distâncias genéticas geradas, foram construídos três dendrogramas, utilizando o método de agrupamento das médias das distâncias (UPGMA). Para a estimativa do ajuste entre a matriz de dissimilaridade e o dendrograma gerado, foi calculado o coeficiente de correlação cofenética ( $r$ ) (SOKAL \& ROHLF 1962), utilizando o programa computacional NTSYS pc 2.1 (ROHLF 2000).

A partir das distintas estimativas de distância genética, estimadas no presente trabalho, as matrizes de dados foram utilizadas para cálculo da correlação (associação) entre as mesmas. Para este cálculo foi empregado o teste de comparação de matrizes de Mantel, com 1000 permutações (MANTEL 1967), utilizando o programa computacional NTSYS pc 2.1 (ROHLF 2000).

\section{RESULTADOS E DISCUSSÃO}

$\mathrm{Na}$ Tabela 1 estão os dados dos caracteres qualitativos, mensurados em 16 genótipos de arroz avaliados a campo e em casa de vegetação. Em análise preliminar dos dados pode-se observar o comportamento similar entre as mensurações realizadas nos dois experimentos, indicando reduzida participação do ambiente de cultivo na expressão da maioria dos caracteres avaliados, exceto para tipo de panícula (TP). Em termos genéticos isto já era esperado, pois caracteres que expressam reduzido número de classes fenotípicas por ocasião da recombinação gênica, como é o caso da maioria dos descritores de arroz e que fazem parte do presente estudo, são conhecidos como de herança qualitativa, e teoricamente sofrem menor participação dos efeitos de ambiente.

De modo geral, os genótipos estudados apresentaram diferenças em todos os caracteres descritores de arroz, onde foi observado no mínimo a presença de duas classes fenotípicas distintas. Do total de caracteres empregados, o tipo de panícula (TP) e a coloração das glumas (CG) foram os que menos diferenciaram os genótipos. Para TP, as mensurações de campo indicaram somente o genótipo BR IRGA 409 com panículas intermediárias, entretanto, em casa de vegetação, a maioria dos genótipos apresentou esta característica, excetuando IAS 12-9 Formosa e BRS Bojuru, com panículas compactas. Já para o caráter CG, somente o BR IRGA 411 se apresentou distinto em relação aos demais genótipos, independente do ambiente avaliado, o que demonstra elevada similaridade entre as constituições genéticas empregadas no estudo.

Em relação ao comportamento dos genótipos frente aos caracteres considerados quantitativos, a análise de variância mostrou diferenças significativas $(p<0,01)$ para todas as variáveis estudadas (Tabela 2). De imediato, isto indica a presença de variabilidade genética entre os distintos genótipos avaliados e possibilita a inclusão dos referidos caracteres nos estudos de distância genética.

Diferentemente do observado para os caracteres qualitativos, a análise dos quadrados médios para a fonte de variação de ambiente permitiu verificar diferenças para a maioria dos caracteres, exceto espessura do colmo (EC), espessura do grão sem casca (EGSC) e relação de comprimento e largura dos grãos $\left(\mathrm{C} \mathrm{L}^{-1}\right)$, indicando elevada participação do ambiente na expressão desta classificação de caracteres. Estes dados podem ser justificados pelo fato de serem caracteres controlados por elevado número de genes, o que resulta em maior número de classes fenotípicas e favorece a maior participação dos efeitos do ambiente.

É possível constatar ainda a presença de interação genótipo $x$ ambiente nos caracteres altura de planta (AP), comprimento do colmo (CC), comprimento da panícula (CP), ciclo vegetativo (CV), massa de 
panícula (MP), comprimento da panícula (CP), número de grãos degranados (NGD) e número de grãos por panícula (NGP). O comportamento diferenciado dos genótipos estudados, constatada pela presença de interação frente aos efeitos dos distintos ambientes empregados, implica na necessidade de ampliar o número de avaliações (locais e/ou anos) como forma de aumentar a confiabilidade dos dados destes caracteres. Assim, quanto maior o número de locais ou anos de repetições, melhor será a credibilidade na caracterização dos genótipos.

Tabela 1. Caracteres qualitativos (descritores em arroz) avaliados em 16 genótipos e o ideotipo de arroz, em experimentos a campo e em casa de vegetação.

Table 1. Qualitative characteristics (descriptors in rice) evaluated in 16 genotypes and ideotype of rice in field and greenhouse experiments.

\begin{tabular}{|c|c|c|c|c|c|c|c|c|c|}
\hline \multirow{2}{*}{ Ambiente } & \multirow{2}{*}{ Genótipo } & \multicolumn{8}{|c|}{ Caracteres * } \\
\hline & & $\mathrm{CF}$ & $\mathrm{PF}$ & AFB & TP & EP & $P G$ & $\mathrm{CG}$ & $\mathrm{FG}$ \\
\hline Campo & IAS 12-9 Formosa & 2 & 4 & 3 & 1 & 1 & 4 & 1 & 2 \\
\hline Campo & BR IRGA 409 & 2 & 4 & 1 & 2 & 2 & 4 & 1 & 4 \\
\hline Campo & BR IRGA 410 & 2 & 4 & 1 & 1 & 2 & 4 & 1 & 4 \\
\hline Campo & BR IRGA 411 & 2 & 1 & 2 & 1 & $\overline{1}$ & 1 & 2 & 4 \\
\hline Campo & BR IRGA 412 & 2 & 1 & 1 & 1 & 2 & 1 & 1 & 4 \\
\hline Campo & BR IRGA 413 & 2 & 1 & 1 & 1 & 2 & 1 & 1 & 4 \\
\hline Campo & BR IRGA 414 & 2 & 1 & 1 & 1 & 2 & 1 & 1 & 4 \\
\hline Campo & BRS 6 Chuí & 2 & 1 & 1 & 1 & 2 & 1 & 1 & 4 \\
\hline Campo & BRS 7 Taim & 2 & 1 & 1 & 1 & 2 & 1 & 1 & 4 \\
\hline Campo & BRS Ligeirinho & 1 & 1 & 1 & 1 & 1 & 1 & 1 & 4 \\
\hline Campo & BRS Agrisul & 2 & 1 & 1 & 1 & 2 & 1 & 1 & 4 \\
\hline Campo & BRS Bojuru & 2 & 4 & 3 & 1 & 1 & 4 & 1 & 2 \\
\hline Campo & BRS Firmeza & 3 & 1 & 1 & 1 & 1 & 1 & 1 & 4 \\
\hline Campo & BRS Atalanta & 1 & 1 & 1 & 1 & 1 & 1 & 1 & 4 \\
\hline Campo & BRS Pelota & 2 & 4 & 1 & 1 & 2 & 4 & 1 & 4 \\
\hline Campo & BRS Querência & 2 & 1 & 2 & 1 & 2 & 1 & 1 & 4 \\
\hline Casa de vegetação & IAS 12-9 Formosa & 2 & 4 & 3 & 1 & 1 & 4 & 1 & 2 \\
\hline Casa de vegetação & BR IRGA 409 & 2 & 4 & 1 & 2 & 2 & 4 & 1 & 4 \\
\hline Casa de vegetação & BR IRGA 410 & 2 & 4 & 1 & 2 & 2 & 4 & 1 & 5 \\
\hline Casa de vegetação & BR IRGA 411 & 2 & 1 & 2 & 2 & 1 & 1 & 2 & 4 \\
\hline Casa de vegetação & BR IRGA 412 & 2 & 1 & 1 & 2 & 2 & 1 & 1 & 4 \\
\hline Casa de vegetação & BR IRGA 413 & 2 & 1 & 1 & 2 & 2 & 1 & 1 & 4 \\
\hline Casa de vegetação & BR IRGA 414 & 2 & 1 & 1 & 2 & 2 & 1 & 1 & 4 \\
\hline Casa de vegetação & BRS 6 Chuí & 2 & 1 & 1 & 2 & 2 & 1 & 1 & 4 \\
\hline Casa de vegetação & BRS 7 Taim & 2 & 1 & 1 & 2 & 2 & 1 & 1 & 4 \\
\hline Casa de vegetação & BRS Ligeirinho & 1 & 1 & 1 & 2 & 2 & 1 & 1 & 4 \\
\hline Casa de vegetação & BRS Agrisul & 2 & 1 & 1 & 2 & 2 & 1 & 1 & 4 \\
\hline Casa de vegetação & BRS Bojuru & 2 & 4 & 2 & 1 & 1 & 4 & 1 & 2 \\
\hline Casa de vegetação & BRS Firmeza & 3 & 1 & 1 & 2 & 2 & 1 & 1 & 4 \\
\hline Casa de vegetação & BRS Atalanta & 1 & 1 & 1 & 2 & 2 & 1 & 1 & 5 \\
\hline Casa de vegetação & BRS Pelota & 2 & 4 & 1 & 2 & 2 & 4 & 1 & 4 \\
\hline Casa de vegetação & BRS Querência & 2 & 1 & 2 & 2 & 2 & 1 & 1 & 4 \\
\hline
\end{tabular}

${ }^{*} \mathrm{CF}$ = Cor da Folha (1= verde claro; $2=$ verde; $3=$ verde escuro); PF = Pubescência da Folha (1= ausente; 4= forte); AFB = Ângulo da Folha Bandeira ( $1=$ ereto; $2=$ intermediário; $3=$ horizontal; $4=$ descendente); TP = Tipo de Panícula ( $1=$ compacta; $2=$ intermediária); EP = Exerção da Panícula ( $1=$ completa; $2=$ média); $P G=$ Pubescência das Glumelas $(1=$ ausente; $4=$ forte.); CG = Coloração da Glumelas (1= amarelo-palha; 2= dourada); FG = Forma do Grão (2=semi-arredondada; 4= alongada; 5= muito alongada).

A análise da dissimilaridade entre os 16 genótipos de arroz empregados no estudo gerou dendrogramas que representam as estimativas de distância genética individuais e conjunta dos genótipos, por meio do emprego da análise dos caracteres avaliados nos dois ambientes. A principal vantagem da utilização desta ferramenta está na possibilidade de reunir diversas variáveis em apenas uma análise.

Aliado a esses estudos, também é necessário que os genótipos destinados a hibridações associem elevado desempenho individual e aspectos de adaptabilidade e estabilidade para produtividade de grãos ou outros caracteres de interesse do melhorista. Assim, existe grande possibilidade de seleção de genótipos transgressivos, sendo que, genótipos com elevada produtividade, porém distantes geneticamente, podem apresentar locos distintos controlando o caráter e expressando elevada capacidade de combinação (STRECK et al. 2017).

A Figura 1, demonstra certa uniformidade na distribuição dos grupos de genótipos em relação aos três dendrogramas representativos da distância genética individual dos caracteres qualitativos, tanto mensurados a campo, em casa de vegetação, quanto na análise conjunta de ambos. Isto é indicativo da existência de um padrão bem definido quando da seleção destas constituições genéticas acentuando a 
uniformidade para esta classificação de caracteres. A partir da divisão de grupos de genótipos definida pela similaridade média (a), os caracteres qualitativos mensurados a campo, em casa de vegetação e na média dos dois ambientes, propiciaram a formação de quatro grupos distintos.

Tabela 2. Resumo das análises de variância conjunta para os caracteres fenotípicos utilizados para estimar a distância genética entre 16 cultivares de arroz e o ideotipo avaliados neste estudo.

Table 2. Summary of joint analyses of variance for the phenotypic characteristics used to estimate the genetic distance between 16 rice cultivars and the ideotype evaluated in this study.

\begin{tabular}{lllllllll}
\hline FV (GL) & \multicolumn{7}{c}{ Quadrado Médio (QM) } \\
\cline { 2 - 9 } & AP & CC & CFB & LFB & EC & CP & CV & MP \\
\hline QM Genótipos (16) & $336,75^{*}$ & $381,90^{*}$ & $37,19^{*}$ & $18,54^{*}$ & $1,32^{*}$ & $25,81^{*}$ & $691,79^{*}$ & $1,99^{*}$ \\
QM ambiente (1) & $654,00^{*}$ & $1010,96^{*}$ & $156,33^{*}$ & $9,09^{*}$ & 0,02 & $31,57^{*}$ & $2733,17^{*}$ & $13,94^{*}$ \\
QM G X A (16) & $20,66^{*}$ & $26,20^{*}$ & 6,49 & 0,34 & 0,14 & $1,80^{*}$ & $28,21^{*}$ & $0,80^{*}$ \\
QM resíduo (64) & 3,50 & 3,53 & 6,97 & 0,32 & 0,08 & 0,92 & 5,30 & 0,12 \\
Média & 83,85 & 62,49 & 27,96 & 14,10 & 3,91 & 22,09 & 86,33 & 3,40 \\
CV (\%) & 2,23 & 3,00 & 9,44 & 4,04 & 7,58 & 4,34 & 2,66 & 10,33 \\
\hline FV (GL) & & & \multicolumn{7}{c}{ Quadrado Médio (QM) } & & \\
& NGP & NGD & NGE & MMG & CGSC & LGSC & EGSC & C L $^{-1}$ \\
\hline QM Genótipos (16) & $38,75^{*}$ & $4626,29^{*}$ & $291,93^{*}$ & $16,08^{*}$ & $2,83^{*}$ & $0,45^{*}$ & $0,10^{*}$ & $1,81^{*}$ \\
QM ambiente (1) & $362,39^{*}$ & $19024,0^{*}$ & 1932,70 & $29,61^{*}$ & $0,18^{*}$ & $0,02^{*}$ & 0,01 & 0,01 \\
QM G X A (16) & $9,71^{*}$ & $565,00^{*}$ & 45,70 & 0,84 & 0,01 & 0,01 & 0,01 & 0,01 \\
QM resíduo (64) & 4,53 & 226,26 & 17,45 & 0,95 & 0,01 & 0,01 & 0,01 & 0,01 \\
Média & 6,23 & 126,42 & 16,23 & 25,31 & 6,61 & 2,12 & 1,66 & 3,17 \\
CV (\%) & 21,14 & 11,89 & 19,73 & 3,85 & 1,66 & 4,27 & 4,13 & 3,71
\end{tabular}

$\overline{\mathrm{FV}}=$ fontes de variação, $\mathrm{GL}=$ graus de liberdade, $\mathrm{AP}=$ Altura de planta, $\mathrm{CC}=$ Comprimento do colmo, $\mathrm{CFB}=$ Comprimento da folha bandeira, $\mathrm{LFB}=$ Largura da folha bandeira, $\mathrm{EC}=$ Espessura do colmo, $\mathrm{CP}=$ Comprimento da panícula, $\mathrm{CV}=\mathrm{Ciclo}$ vegetativo, $\mathrm{MP}=$ Massa de panícula, NGD = Número de grãos degranados, NGP = Número de grãos por panícula, NGE = Número de grãos estéreis, MMG = Massa de mil grãos, CGSC = Comprimento de grãos sem casca, LGSC = Largura de grãos sem casca, EGSC = Espessura do grão sem casca, $C L^{-1}=$ Relação de comprimento por largura dos grãos; * significativo pelo teste $F$ a $1 \%$ de probabilidade $(P<0,01)$.

No grupo com maior número de genótipos, é possível verificar a existência de cultivares que representam perfeita similaridade genética (zero de distância genética), independente do ambiente avaliado. Este subgrupo, dentro do grande grupo de mais similares, é composto pelo BR IRGA 412, BR IRGA 413, BR IRGA 414, BRS 6 Chuí, BRS 7 Taim e BRS Firmeza. Levando em consideração que estes fazem parte de único programa de melhoramento genético, é possível afirmar, com grande segurança, que os mesmos possuem genes similares controlando a manifestação fenotípica dos caracteres qualitativos avaliados como descritores em arroz.

O genótipo BRS Agrisul quando avaliado em casa de vegetação também fez parte do sub-grupo de genótipos com similaridade igual a zero, porém, a campo e na análise conjunta este se apresentou separadamente. Além do BRS Agrisul, os genótipos BRS Ligeirinho, BRS Atalanta e BRS Querência diferem dos mais similares, porém, participam do mesmo agrupamento pelo critério da similaridade média (a).

Quando o objetivo for recomendar cruzamentos artificiais entre os genótipos mais divergentes, a partir dos caracteres qualitativos é possível indicar a combinação de quaisquer genótipos pertencentes ao grande grupo descrito anteriormente com o BRS IRGA 411, BRS IRGA 409, IAS 12-9 Formosa ou BRS Bojuru e BRS IRGA 410 ou BRS Pelota que pertencem a grupos distintos na análise da distância genética.

A inclusão do ideotipo na análise da distância genética indicou que o grande grupo de genótipos classificados como os mais similares, incluindo aqueles de similaridade igual a zero, fazem parte do "background" considerado como ideal pelos critérios dos melhoristas de arroz. Desta forma, quando se deseja disponibilizar genitores potenciais para geração de populações segregantes com variabilidade genética superior nos caracteres qualitativos em arroz, deve-se dar preferência pela inclusão destes genótipos que são próximos do ideotipo.

Contudo, a maior ampliação da variabilidade genética para estes caracteres, como forma de ampliar seleção de indivíduos em classes fenotípicas distintas, deve-se então optar pela inclusão de genótipos de grupos distintos observados na análise de distância genética. Os coeficientes de correlação cofenética dos 
dendrogramas A, B e C (0,72; 0,75 e 0,73 respectivamente), evidenciaram um bom ajuste entre as representações gráficas das distâncias e a suas matrizes originais (ROHLF 2000), o que indica boa confiabilidade nas inferências realizadas por meio da avaliação visual da Figura 1.

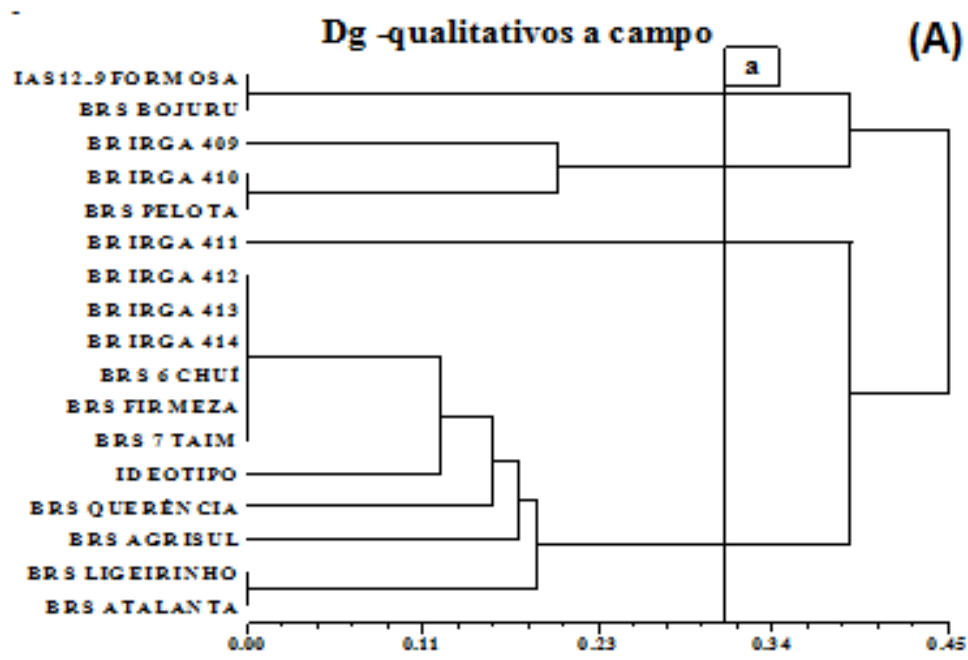

Dg -qualitativos em casa-de-vegetação

(B)

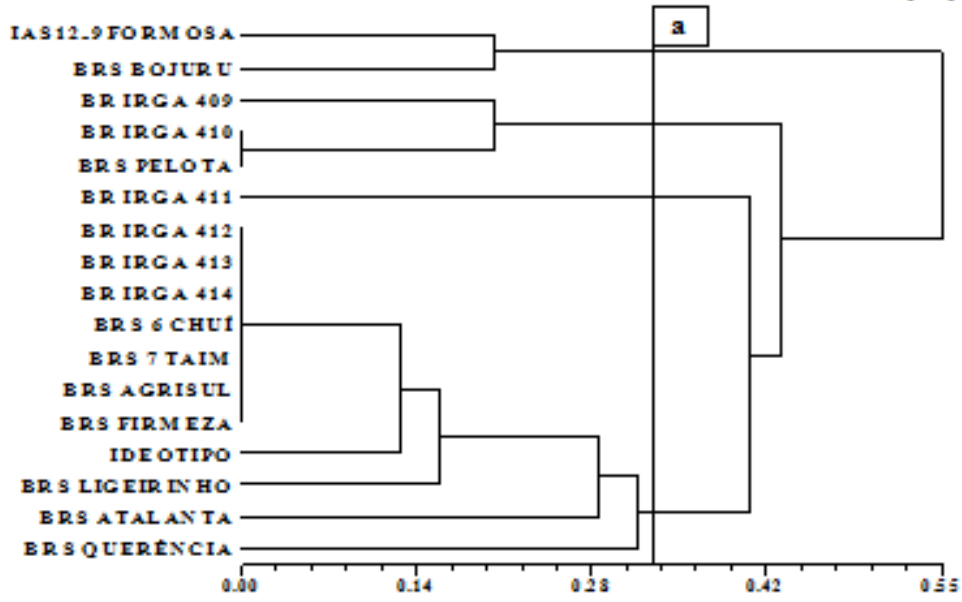

Dg - qualitativos conjunta (campo e casa-de-vegatação) (C)

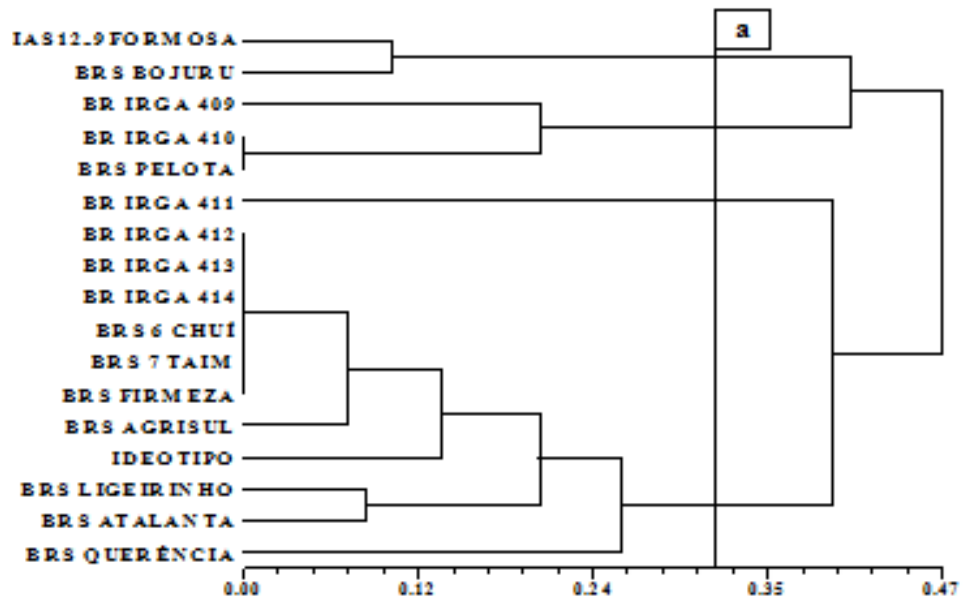

Figura 1. Dendrogramas resultante da análise de 16 genótipos de arroz e o ideotipo, obtido pelo método de agrupamento UPGMA, utilizando o coeficiente (c) como medida de distância genética, com base em oito caracteres qualitativos ( $a=$ similaridade média). ( $A$ correlação cofenética foi de: $A=0,72$, $\mathrm{B}=0,75$ e $\mathrm{C}=0,73)$.

Figure 1. Dendrograms resulting from analysis of 16 rice genotypes and ideotype obtained through UPGMA, using the coefficient (c) as a measure of genetic distance based on eight qualitative characteristics ( $a=$ average similarity) (Cophenetic correlation: $A=0.72, B=0.75$ and $C=0.73$ ). 
Quando a distância genética foi estimada a partir dos caracteres quantitativos (Figura 2), os dendrogramas resultantes da análise individual a campo, em casa de vegetação e da conjunta de ambos os ambientes possibilitou a formação de dois grupos bem definidos de genótipos. O primeiro grupo ficou definido somente pelos genótipos IAS 12-9 Formosa e o BRS Bojuru pelo fato de serem constituições genéticas pertencentes ao grupo de grão japônico.

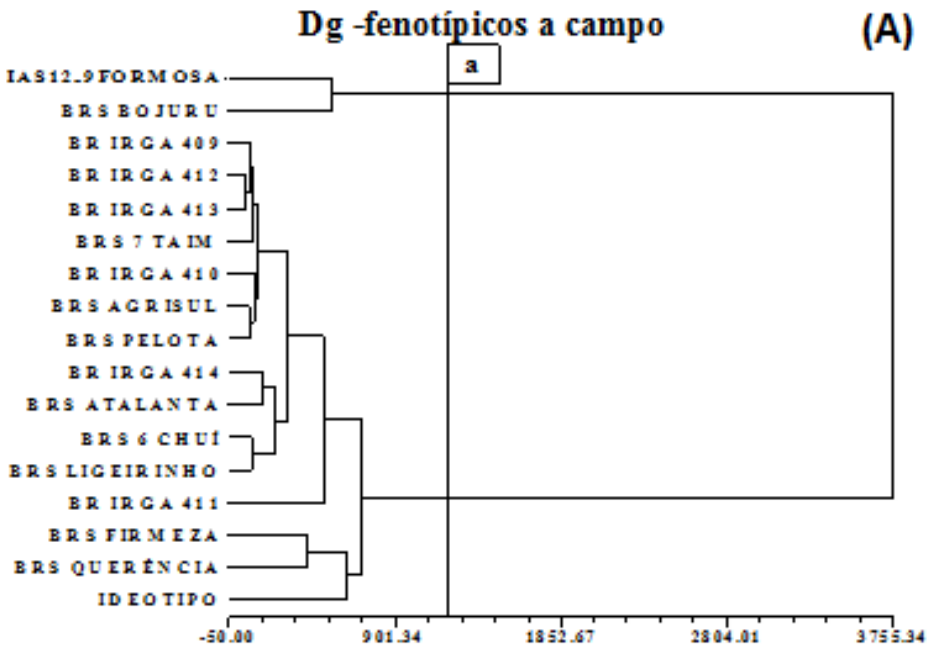

Dg - fenotípicos em casa-de-vegetação

(B)

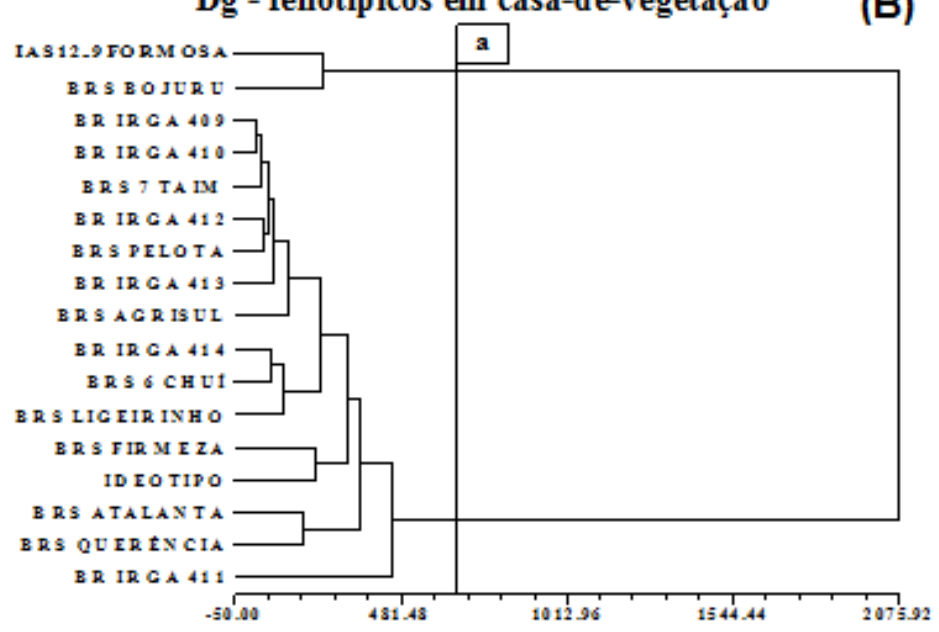

Dg - fenotípicos conjunta (campo e casa-de-vegatação) (C)

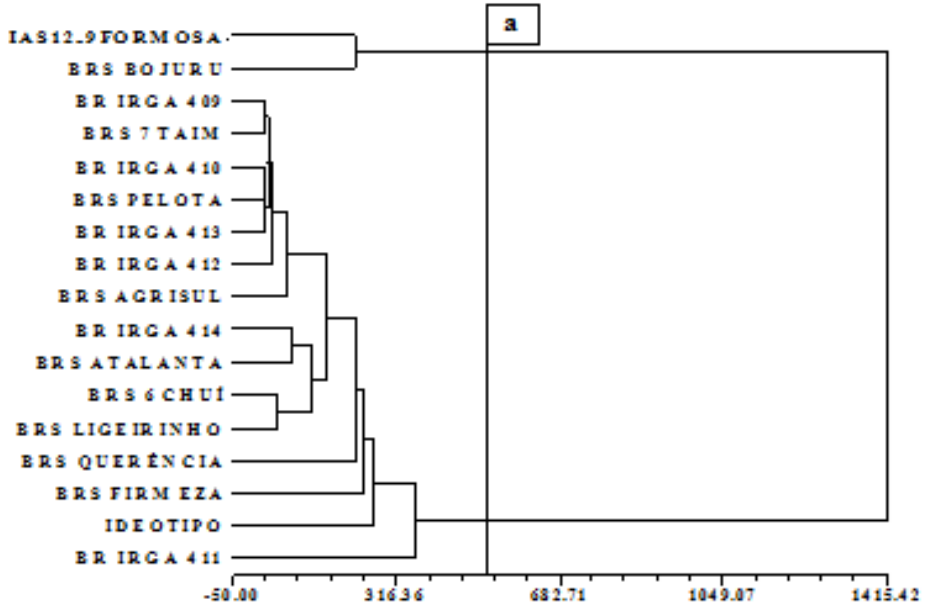

Figura 2. Dendrogramas resultante da análise de 16 genótipos de arroz e o ideotipo, obtido pelo método de agrupamento UPGMA, utilizando a distância de Mahalanobis como medida de distância genética, com base em 16 caracteres fenotípicos quantitativos (a = similaridade média). ( $\mathrm{A}$ correlação cofenética foi de: $A=0,90, B=0,88$ e $C=0,93$ ).

Figure 2. Dendrograms resulting from analysis of 16 rice genotypes and ideotype obtained through UPGMA, using Mahalanobis distance as a measure of genetic distance based on phenotypic characteristics 16 ( $a$ = average similarity). (Cophenetic correlation: $A=0.90, B=0.88$ and $C=0.93$ ). 
O agrupamento incluindo todos os demais genótipos, com elevada similaridade genética entre si, pode ser interpretado pelo fato dos genótipos terem sofrido forte pressão de seleção pelos melhoristas, com objetivo de disponibilizar um biótipo de planta considerado ideal em arroz. Segundo TERRES et al. (2004) no desenvolvimento de uma cultivar de arroz irrigado, são consideradas pelos programas de melhoramento características importantes, como o potencial produtivo; a qualidade industrial; comercial e culinária do grão; tipo de grão; ciclo biológico; altura da planta; reação à doenças e insetos; reação ao frio, à toxicidade por ferro e à salinização do solo e da água.

Neste sentido, torna-se inevitável a busca destes caracteres nos genótipos utilizados na lavoura orizícola gaúcha, selecionando assim genes similares. No Brasil, observou-se que as cultivares de arroz irrigado mais cultivadas são oriundas do cruzamento de sete variedades ancestrais, que são responsáveis por cerca de $81 \%$ do conjunto gênico. Especificamente no Rio Grande do Sul, apenas seis ancestrais (Deogeo-woo-gen, Cina, Lati Sail, I Geo Tze, Mong Chim Vang A e Belle Patna) contribuem com $86 \%$ dos genes das variedades de arroz mais cultivadas (RANGEL et al. 1996).

Historicamente, os cruzamentos realizados nos diferentes programas de melhoramento de arroz concentraram-se na utilização de germoplasma cultivado. O processo de domesticação de uma planta resulta na seleção de características importantes para a sobrevivência da população nas condições em que está sendo trabalhada. Isto resulta no chamado "efeito de afunilamento" em termos de diversidade genética, ou seja, a partir de um "background" genético bastante rico, alguns grupos de genes de interesse vão sendo mantidos na população e outros eliminados (MAGALHÃES JÚNIOR 2007). Este estreitamento do pool genético de cultivares tornam as culturas vulneráveis tanto a estresses bióticos e abióticos, assim, prejudicando ganhos genéticos futuros significativos (BRESEGHELLO \& COELHO 2013).

A descoberta do gene sd-1, responsável pelo porte baixo (semi-anão) em arroz é o maior exemplo de utilização de uma mesma fonte genética, representada pela variedade Índica Tropical IR8, selecionada do cruzamento entre Peta e a variedade Dee-geo-woo-gen. Os estudos ilustraram que se tratava de uma herança simples recessiva (BEACHELL et al. 1972). A inclusão desta característica nos genótipos de arroz provocou a denominada revolução verde no arroz, pois possibilitou um incremento na produtividade fundamentada principalmente no alto perfilhamento e na resposta a elevados níveis de adubação nitrogenada. Esta nova arquitetura de planta permitiu elevar o potencial de produtividade do arroz, com os lançamentos das cultivares BR IRGA 409 e BR IRGA 410, no Rio Grande do Sul (STRECK et al. 2017).

Esse novo tipo de planta caracteriza-se pela baixa estatura, alto perfilhamento, colmos fortes e folhas eretas e verde-escuras, características estas, extremamente efetivas no aumento da produtividade das áreas cultivadas com arroz (TERRES et al. 1999). Atualmente, mais de $60 \%$ da área mundial é coberta por cultivares semi-anãs. No Rio Grande do Sul, as variedades tradicionais são, atualmente, muito pouco cultivadas. Persistem apenas nas comunidades mais tradicionais e, em nível nacional, são pouco relevantes para o abastecimento do mercado interno (TERRES et al. 2004).

O ideotipo criado para os caracteres quantitativos, independentemente do ambiente avaliado, ficou incluído no grande grupo de genótipos definidos pelo critério da similaridade média. Os genótipos BRS Firmeza, BR IRGA 411 e o BRS Querência na maioria das vezes se apresentaram junto aos mais próximos do ideotipo, sugerindo que possuem genes considerados ideais para uso em programas de melhoramento de arroz. Desta maneira, cruzamentos a partir destes genótipos com aqueles mais distantes geneticamente, como por exemplo, o IAS 12-9 Formosa e BRS Bojuru, aumentando a probabilidade de obtenção de populações segregantes superiores para os caracteres agronômicos quantitativos.

Entretanto, para a composição dos blocos de cruzamentos, além da distância genética, o melhorista deve sempre observar os genitores que apresentam médias elevadas nos caracteres de maior interesse em seu programa de melhoramento, para que além da presença de variabilidade genética, as populações segregantes apontem maior número de indivíduos geneticamente superiores (segregantes transgressivos).

Os coeficientes de correlação cofenética dos dendrogramas A, B e C $(0,90,0,88$ e 0,93 , respectivamente), evidenciaram um bom ajuste entre as representações gráficas da distância genética e a suas matrizes originais (ROHLF 2000), o que indica confiabilidade nas inferências realizadas por meio da avaliação visual da Figura 2.

A análise de distância genética obtida de forma conjunta, considerando os experimentos a campo e em casa de vegetação, incluindo também as duas classificações de caracteres (qualitativos e quantitativos), evidenciou ampla variabilidade genética entre os genótipos estudados (Figura 3).

A formação de quatro grupos distintos pela similaridade média, na análise conjunta, apresenta discordância na discriminação dos agrupamentos formados pelos 16 genótipos estudados quando em comparação com as análises individuais. O ideotipo, neste caso, formou grupo isolado em relação aos 
demais genótipos, entretanto, apesar da elevada distância genética, manteve ligação primeiramente com o IAS 12-9 Formosa, BRS Pelota e BRS Querência. Desta forma, estas três constituições genéticas são indicadas como prioritárias para compor blocos de cruzamentos em combinação com quaisquer genótipos pertencentes aos demais grupos, desde que, apresentem médias elevadas nos caracteres de importância agronômica.

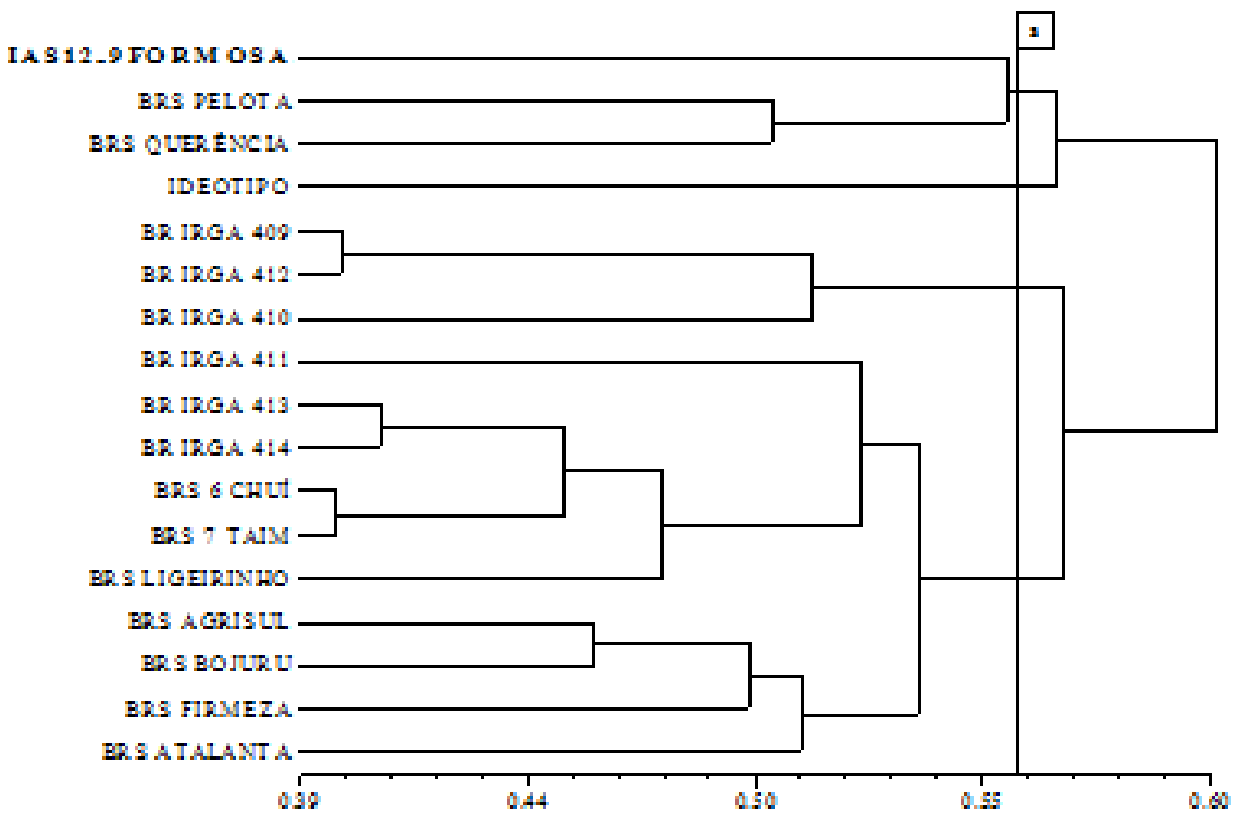

Figura 3. Dendrograma resultante da análise de agrupamento de 16 genótipos de arroz e o ideotipo, obtido pelo método UPGMA, utilizando o complemento do índice de similaridade de GOWER (1971), obtido a partir da análise conjunta de caracteres qualitativos e fenotípicos como medida de distância genética, ou seja, a média dos experimentos realizados a campo e em casa de vegetação ( $a$ = similaridade média) (A correlação cofenética foi de 0,90 ).

Figure 3. Dendrogram resulting from cluster analysis of 16 rice genotypes and ideotype obtained through UPGMA, using the complement Gower similarity index (1971), obtained from joint analysis of qualitative and phenotypic characteristics as a measure of distance genetics, i.e. the average of experiments carried out in the field and in the greenhouse ( $a=$ average similarity) (Cophenetic correlation: 0.90).

A avaliação dos distintos genótipos de arroz em duas condições de ambiente acrescido da divisão dos caracteres também em dois grupos (qualitativos e quantitativos) auxilia no entendimento das possíveis afinidades que alguns genótipos podem apresentar em situações de ambiente específico, direcionando os esforços dos pesquisadores dentro do programa de melhoramento genético. Neste sentido, a existência de comportamento diferenciado dos genitores frente as variações de ambiente e classes de caracteres testadas neste trabalho propiciou estimativas de coeficientes de correlação variando de elevada à reduzida magnitude (Tabela 3).

As matrizes de distância genética entre os genótipos com base nos caracteres qualitativos aferidos a

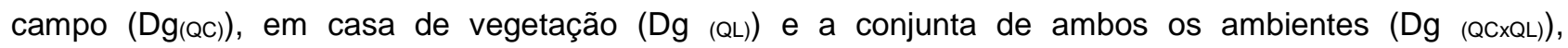
evidenciaram associação elevada entre si $\left(D_{(Q C)} \times D_{(Q L)}=0,91 ; g_{(Q C)} \times D_{(Q C \times Q L)}=0,97\right.$ e $D_{(Q L)} \times D g$ $(Q C \times Q L)=0,98)$, indicando que possivelmente a avaliação destes caracteres poderá ser realizada efetivamente sob apenas um dos critérios.

Da mesma maneira, as matrizes de distância estimadas com base nos caracteres quantitativos aferidos nos distintos ambientes também mostraram elevada associação entre si e com a análise conjunta de ambos. Porém, quando foram correlacionadas as matrizes de distância das duas classificações de caracteres, com aquelas resultantes das duas variações de ambiente, os coeficientes de correlação foram de magnitude intermediária. Comprovando que a participação do ambiente, acompanhado das interações genéticas apresentadas pelos distintos genótipos avaliados, exerce influência diferenciada para os caracteres qualitativos em comparação aos quantitativos, devendo-se principalmente pelos fatores genéticos relacionados à herança dos mesmos. 
Tabela 3. Correlações obtidas entre as matrizes de distância genética de 16 genótipos de arroz e o ideotipo, com base nos caracteres qualitativos avaliados a campo (Dg-(QC)), qualitativos avaliados em casa de vegetação (Dg-(Qcv)), conjunta dos qualitativos a campo e em casa de vegetação (Dg-(QC x Qcv)), caracteres quantitativos fenotípicos avaliados a campo ( $\mathrm{Dg}-(\mathrm{FC})$ ), caracteres quantitativos fenotípicos avaliados em casa de vegetação (Dg-(FCV)), conjunta dos caracteres quantitativos fenotípicos avaliados a campo e em casa de vegetação ( $\mathrm{Dg}-(\mathrm{FC} \times \mathrm{FCV})$ ) e conjunta dos caracteres qualitativos e quantitativos fenotípicos $(\mathrm{Dg}-(\mathrm{Q} \times \mathrm{F}))$.

Table 3. Correlations obtained between the matrices of genetic distance of 16 rice genotypes and ideotype based on qualitative characteristics evaluated in the field ( $\left.D g_{-(Q C)}\right)$, in greenhouse ( $\left.D g_{-(Q C V)}\right)$, joint analysis of qualitative characteristics in the field and greenhouse (Dg-(QC $\times$ QCV) $)$, phenotypic quantitative traits evaluated in the field $\left(D g_{-(F C)}\right)$, in a greenhouse $\left(D g_{-(F C V)}\right)$, and joint analysis of quantitative traits evaluated the field and greenhouse $\left(D G_{-(F C \times F C V)}\right)$ and joint analysis of qualitative and quantitative characters $\left(D g_{-(Q \times F)}\right)$.

\begin{tabular}{lllllll}
\hline & $\mathrm{Dg}-(\mathrm{QCV})$ & $\mathrm{Dg}-(\mathrm{QC} \times \mathrm{QCV})$ & $\mathrm{Dg}-(\mathrm{FC})$ & $\mathrm{Dg}-(\mathrm{FCV})$ & $\mathrm{Dg}-(\mathrm{FC} \times \mathrm{FCV})$ & $\mathrm{Dg}-(\mathrm{Q} \times \mathrm{F})$ \\
\hline $\mathrm{Dg}-(\mathrm{QC})$ & $0,91^{*}$ & $0,97^{*}$ & 0,46 & $0,54^{*}$ & $0,51^{*}$ & 0,23 \\
$\mathrm{Dg}-(\mathrm{QCV})$ & & $0,98^{*}$ & $0,48^{*}$ & $0,60^{*}$ & $0,53^{*}$ & 0,25 \\
$\mathrm{Dg}-(\mathrm{QC} \times \mathrm{QCV})$ & & & $0,48^{*}$ & $0,59^{*}$ & $0,54^{*}$ & 0,24 \\
$\mathrm{Dg}-(\mathrm{FC})$ & & & $0,96^{*}$ & $0,98^{*}$ & 0,14 \\
$\mathrm{Dg}-(\mathrm{FCV})$ & & & & $0,97^{*}$ & 0,10 \\
$\mathrm{Dg}-(\mathrm{FC} \times \mathrm{FCV})$ & & & & & 0,13 \\
\hline
\end{tabular}

* Correlação significativa a 5\% de probabilidade pelo teste de Mantel com 1000 permutações.

\section{CONCLUSÃO}

Existe estreita distância genética entre as cultivares de arroz irrigada lançadas pelo programa de melhoramento genético da Embrapa Clima Temperado dentro do grupo Índica.

As matrizes de distância genética entre os genótipos com base nos caracteres qualitativos aferidos a campo, em casa de vegetação e a conjunta de ambos os ambientes, evidenciaram associação elevada entre si.

A associação das matrizes de distância genética entre os genótipos com base nos caracteres qualitativos e quantitativos com a matriz conjunta de ambos os ambientes, evidenciaram elevada participação do ambiente.

\section{REFERÊNCIAS}

BEACHELL HM et al. 1972. IRRI's international breeding program. In: International Rice Research Institute. Rice Breeding. Philippines: Los Banõs. p. 89-106.

BRESEGHELLO F \& COELHO ASG. 2013. Traditional and Modern Plant Breeding Methods with Examples in Rice (Oryza sativa L.). Journal of Agricultural and Food Chemistry 61: 8277-8286.

BRONDANI C et al. 2006. Determination of genetic variability of traditional varieties of Brazilian rice using microsatellite markers. Genetics and Molecular Biology 29: 676-684.

CRUZ CD. 2013. GENES - a software package for analysis in experimental statistics and quantitative genetics. Acta Scientiarum. Agronomy 35: 271-276.

GOWER JC. 1971. A general coefficient of similarity and some of its properties. Biometrics 27: 857-874.

HARTWIG I et al. 2007. Variabilidade fenotípica de caracteres adaptativos da aveia branca (Avena sativa L.) em cruzamentos dialélicos. Ciência Rural 37: 337-345.

HOSAN SM et al. 2010. Genetic divergence in landraces of bangladesh rice (Oryza sativa L.). A Scientific Journal of Krishi Foundation. The Agriculturists 8: 28-34.

LEE I et al. 2011. Genetic dissection of the biotic stress response using a genome-scale gene network for rice. Proceedings of the National Academy of Sciences 108: 18548-18553.

MAGALHÃES JÚNIOR AM. 2007. Recursos genéticos de arroz (Oryza sativa L.) no Sul do Brasil. Tese (Doutorado em Agronomia). Pelotas: UFPel. 160p.

MANTEL N. 1967. The detection of disease clustering and a generalized regression approach. Cancer Research 27: 209-220.

RANGEL PHN et al. 1996. Base genética das cultivares de arroz (Oryza sativa L.) irrigado do Brasil. Pesquisa Agropecuária Brasileira 31: 349-357.

ROHLF FJ. 2000. NTSYS-pc: numerical taxonomy and multivariate analysis system, version 2.1. Exeter Software Setauket, New York.

SOKAL RR \& ROHLF FJ. 1962. The comparison of dendrograms by objective methods. Taxon 11: 30-40.

STRECK EA et al. 2017. Variabilidade fenotípica de genótipos de arroz irrigado via análise multivariada. Revista Ciência Agronômica 48: 101-109. 
TERRES AL et al. 2004. Melhoramento genético e cultivares de arroz irrigado. In: GOMES A da S \& MAGALHÃES JÚNIOR AM. (eds.). Arroz Irrigado no Sul do Brasil. Pelotas: Embrapa Clima Temperado. p.161-235.

TERRES AL et al. 1999. Arroz irrigado no Rio Grande do Sul: generalidades e cultivares. Pelotas: Embrapa Clima Temperado. 58p. (Circular Técnica 14). 